\title{
The Effect of Biaxial Loading on the Limit Load of Cracked Plates
}

Link to publication record in Manchester Research Explorer

\section{Citation for published version (APA):}

Meek, C., \& Ainsworth, R. (2015). The Effect of Biaxial Loading on the Limit Load of Cracked Plates. In host publication American Society of Mechanical Engineers.

\section{Published in:}

host publication

\section{Citing this paper}

Please note that where the full-text provided on Manchester Research Explorer is the Author Accepted Manuscript or Proof version this may differ from the final Published version. If citing, it is advised that you check and use the publisher's definitive version.

\section{General rights}

Copyright and moral rights for the publications made accessible in the Research Explorer are retained by the authors and/or other copyright owners and it is a condition of accessing publications that users recognise and abide by the legal requirements associated with these rights.

\section{Takedown policy}

If you believe that this document breaches copyright please refer to the University of Manchester's Takedown Procedures [http://man.ac.uk/04Y6Bo] or contact uml.scholarlycommunications@manchester.ac.uk providing relevant details, so we can investigate your claim.

\section{OPEN ACCESS}




\section{THE EFFECT OF BIAXIAL LOADING ON THE LIMIT LOAD OF CRACKED PLATES}

\author{
Caroline Meek \\ The University of Manchester \\ Manchester, UK
}

\author{
Robert A. Ainsworth \\ The University of Manchester \\ Manchester, UK
}

\begin{abstract}
To address the issue of the lack of guidance in fitness-forservice codes [1], [2], for biaxial and triaxial effects on fracture, this paper expands on results presented at PVP 2014 [3] for a centre cracked plate by including the effect of plate length and then presents results for single edge and double edge cracked plates. The results demonstrate that load biaxiality can have a significant effect on the limit load and the crack driving force; reducing the limit load and increasing the crack driving force relative to that for uniaxial loading for negative biaxiality and high positive biaxiality but increasing the limit load and reducing the crack driving force for some intermediate levels close to equibiaxial loading.
\end{abstract}

\section{INTRODUCTION}

There is little guidance in fitness-for-service codes and standards such as R6 [1] and BS 7910 [2] for dealing with biaxial and triaxial loading. Historically there has been research into biaxial loading effects on limit load, crack driving force and fracture toughness using plates, cylinders and cruciform specimens. Most of this research focuses on just the effect of adding a biaxial load and limits this additional loading to around half or 0.6 times the principal load and to equibiaxial loading. Østby and Hellesvik [4] examined the effects of adding internal pressure, finding that adding a biaxial load increases the crack driving force, decreases the strain capacity but has little effect on ductile crack growth resistance. Very few studies have systematically looked at the influence of the level of biaxial loading in terms of the ratio of additional biaxial load to the principal load on failure. O'Dowd et al. [5] examined $\mathbf{J}$ and $\mathrm{Q}$ for centre cracked plates and normalised by a limit load dependent on biaxiality, within a range of biaxial load ratio from 0 to 1 . Meek \& Ainsworth [3], [6], determined the effect of a wide range of biaxial load ratios on the limit load of centre cracked plates. This paper summarises the results of the previous analyses, [3] and uses similar methods and methodology to assess the effects of biaxial load ratio on short centre cracked plates, double edge cracked plates and single edge cracked plates.

\section{NOMENCLATURE}

a Half crack size

B Biaxial load ratio $=\sigma_{1} / \sigma_{2}$

E Young's modulus

$\mathrm{f}(\beta) \quad$ Limit load function

$\mathrm{H} \quad$ Half plate height

J J-integral, elastic-plastic crack tip characterizing parameter

n Work hardening exponent (Ramberg-Osgood)

$\mathrm{n}_{\mathrm{L}} \quad$ Normalised limit load

Q Constraint parameter

W Half plate width

$\alpha \quad$ Work hardening coefficient (Ramberg-Osgood)

$\beta \quad$ Normalised crack size $=\mathrm{a} / \mathrm{W}$

$\gamma \quad$ Von Mises yield stress multiplier $=2 / \sqrt{3}$

$\varepsilon \quad$ Strain

$\varepsilon_{0} \quad$ Normalising strain $=\mathrm{E} / \sigma_{\mathrm{y}}$

$\theta \quad$ Angle of slip-line to horizontal

$\theta_{\mathrm{L}} \quad$ Angle of slip-line to horizontal required to minimise short plate limit load solution

$\sigma_{1} \quad$ Remote applied stress parallel to the crack

$\sigma_{2} \quad$ Remote applied stress normal to the crack

$\sigma_{\mathrm{y}} \quad$ Yield stress

$\left(\sigma_{2}\right)_{\mathrm{L}} \quad$ Limit load solution

$\left(\sigma_{2}\right)_{\mathrm{L}}{ }^{\mathrm{lb}} \quad$ Lower bound solution for limit load

$\left(\sigma_{2}\right)_{\mathrm{L}}{ }^{\mathrm{ub}} \quad$ Upper bound solution for limit load 


\section{FINITE ELEMENT ANALYSIS}

In [3], elastic-plastic plane strain finite element (FE) analyses were described for a centre cracked plate with a semiheight, $\mathrm{H}$, equal to twice the semi-width, $\mathrm{W}$. A wide range of biaxial load ratios, $\mathrm{B}$, and semi-crack size ratios, a/W, were addressed. In this paper, the results of similar FE analyses are presented for shorter centre cracked plates, single edge cracked plates and double edge cracked plates. As the mesh details and FE analysis approach follows that in [3], only analysis results are presented in this paper. Such results are primarily presented as numerical limit loads but some results for $\mathbf{J}$ solutions and deformation patterns are also presented. These observed patterns have been used to develop upper bound limit load solutions using simplified slip-line approaches, as in [3].

Figure 1 and Figure 2 show the deformation patterns at the limit load applied in selected FE analyses for an elasticperfectly plastic centre cracked plate. In each case, the modelled quarter of the centre cracked plate has the crack going from the bottom left corner towards the right. The regions of intense plastic deformation can be seen to correspond to slip-lines going forward or backwards from the crack tip.

\section{CENTRE CRACK PLATE LOWER BOUND LIMIT LOADS}

The lower bound plane strain von Mises solution for long centre cracked plates was obtained in [3] by assuming a stress field such that the horizontal stress at failure throughout the plate is equal to $\sigma_{1}=B \sigma_{2}$ and the vertical stress is zero above the crack and $\sigma_{2} /(1-\mathrm{a} / \mathrm{W})$ above the ligaments. The lower bound limit load thus obtained is given in equation (1)

$$
\left(\sigma_{2}\right)_{\mathrm{L}}^{\mathrm{lb}}=\frac{2 \sigma_{\mathrm{y}}}{\sqrt{3}} \operatorname{Min}\left[\frac{(1-\mathrm{a} / \mathrm{W})}{|1-\mathrm{B}(1-\mathrm{a} / \mathrm{W})|}, \frac{1}{|\mathrm{~B}|}\right]
$$

It has been assumed that for a long plate, the stress field is able to redistribute the vertical stress such that the boundary conditions at the top and bottom surfaces of the plate are satisfied.

The assumption of this stress redistribution and the neglect of shear stress are not valid for short plates. A lower bound solution has been generated by assuming a shear stress above the crack increasing linearly with horizontal distance from 0 at the centre of the plate to $a \sigma_{2} / \mathrm{H}$ at the crack tip then, above the uncracked ligament, decreasing to 0 at the sides of the plate. The vertical stress is assumed to increase from 0 at the cracked mid-plane to $\sigma_{2}$ at the top and bottom surfaces, and above the ligament from $\sigma_{2} /(1-\mathrm{a} / \mathrm{W})$ at the mid-plane to $\sigma_{2}$ at the top and bottom surfaces.

The lower bound limit load thus obtained is given in equation (2).

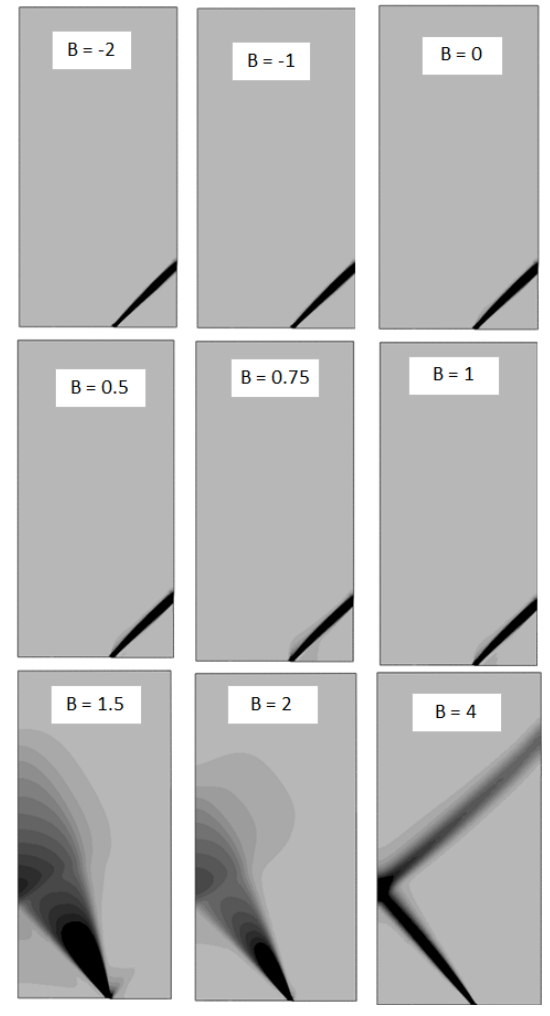

Figure 1: Plastic strain FE output, $a / W=0.6, H / W=2$

$$
\left(\sigma_{2}\right)_{\mathrm{L}}^{\mathrm{lb}}=\frac{2 \sigma_{\mathrm{y}}}{\sqrt{3}} \operatorname{Min}\left[\frac{1}{\left[\mathrm{~B}^{2}+4(\mathrm{a} / \mathrm{H})^{2}\right]^{1 / 2}}, \frac{(1-\mathrm{a} / \mathrm{W})}{\left[\{1-\mathrm{B}(1-\mathrm{a} / \mathrm{W})\}^{2}+4(\mathrm{a} / \mathrm{H})^{2}(1-\mathrm{a} / \mathrm{W})^{2}\right]^{1 / 2}}\right]
$$

Equation (2) reduces to equation (1) for long plates, i.e. when $\mathrm{a} / \mathrm{H} \rightarrow 0$.

\section{CENTRE CRACK PLATE UPPER BOUND LIMIT LOADS}

The upper bound limit load solutions for long centre cracked plates [3] were found by assuming deformation patterns based on observed FE output (Figure 1), such that slip-lines intersect the sides of the plate and equating external work done by the applied forces with the energy dissipated along the slip-lines. The figure shows that the slip-lines travel forwards from the crack for lower values of $B$ and then appear to change direction to reverse slip-lines once $\mathrm{B}>1$, all at angles of $45^{\circ}$ to the horizontal. This is reflected in the two upper bound solutions in equation (3), where the theoretical change-over point is at $\mathrm{B}=1 /\left(1-(\mathrm{a} / \mathrm{W})^{2}\right)>1$. 

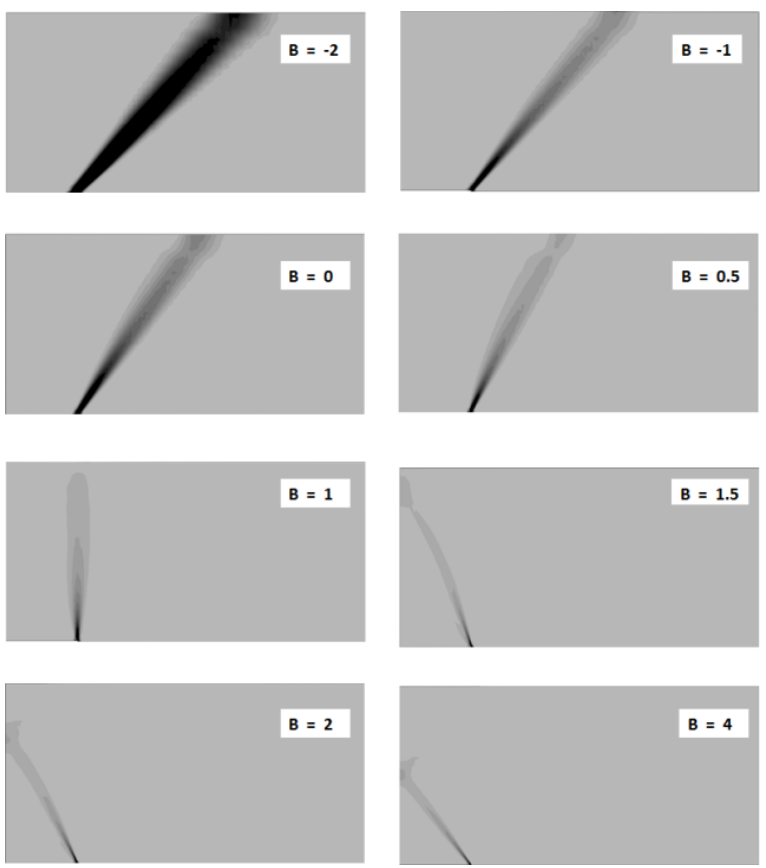

Figure 2: Plastic strain FE output, $a / W=0.2, H / W=0.5$

$$
\left(\sigma_{2}\right)_{\mathrm{L}}^{\mathrm{ub}}=\frac{2 \sigma_{\mathrm{y}}}{\sqrt{3}} \operatorname{Min}\left[\frac{(1-\mathrm{a} / \mathrm{W})}{|1-\mathrm{B}(1-\mathrm{a} / \mathrm{w})|}, \frac{(\mathrm{a} / \mathrm{w}+1)}{|\mathrm{B}(\mathrm{a} / \mathrm{w}+1)-1|}\right]
$$

Note that for lower values of $B$, the value of limit load given by the lower bound equation (1) is equal to that given by the upper bound equation (3) and thus this is an exact solution.

For short plates, the same procedure is followed but with the condition that the slip-lines intersect the top and bottom surfaces of the plate rather than the sides. The solution is more complex as the slip-lines are not at $45^{\circ}$ to the horizontal. They do transition from forward to reverse as B increases; however they do so by getting steeper as B increases to 1, at which point the line is vertical, then the angle decreases again as B increases for the reverse slip line pattern. This can be seen in the FE output shown in Figure 2. Details of the slipline analysis are omitted here but the result is given in equation (4).

$\left(\sigma_{2}\right)_{\mathbf{L}}^{\mathbf{u b}}=$

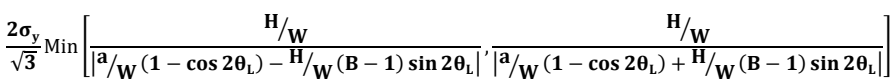
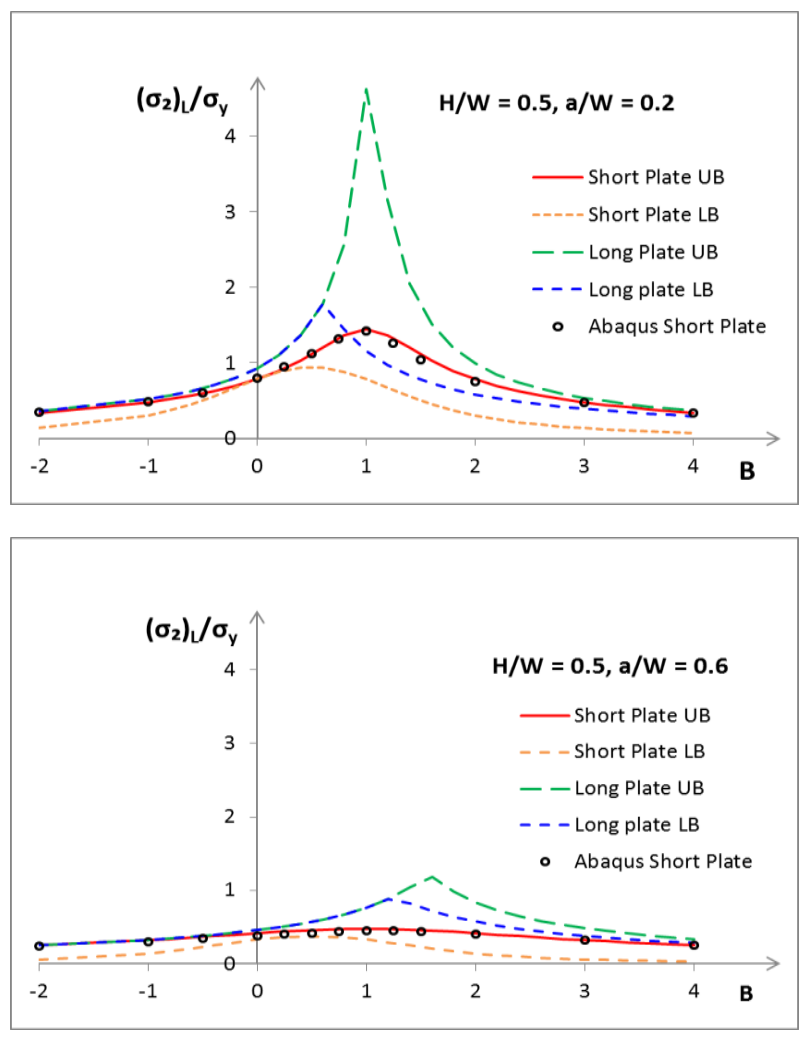

Figure 3: Limit load solutions and FE output for short plates

where $\theta_{\mathrm{L}}=\frac{\pi}{2}-0.5 \tan ^{-1}\left(\frac{\mathrm{H} / \mathrm{W}^{|\mathrm{B}-1|}}{\mathrm{a} / \mathrm{W}}\right)$

The lower and upper bound solutions of equations (1) to (4) are plotted, together with the FE output for short plates, in Figure 3.

For the short plates, there is very good agreement between the FE output and the upper bound limit load solutions of equation (4).

It can be seen clearly that the theoretical limit loads are lower for these short plates (in this case $\mathrm{H} / \mathrm{W}=0.5$ ) than for the long plates (in this case $\mathrm{H} / \mathrm{W}=2$ ) for $\mathrm{a} / \mathrm{W}=0.2$ and for $\mathrm{a} / \mathrm{W}=0.6$.

The $45^{\circ}$ slip-lines meet the sides of the plate when $\mathrm{H}>(\mathrm{W}-\mathrm{a})$, thus $\mathrm{H}=(\mathrm{W}-\mathrm{a})$ defines the minimum value of $\mathrm{H}$ for which the long plate solution can be applicable. The value of $\mathrm{H}$ for which the slip-lines meet the top of the plate, defining a short plate, is more complex as it is dependent on the angle $\theta_{\mathrm{L}}$ which is itself dependent on $\mathrm{H}, \mathrm{W}, \mathrm{a}$ and $\mathrm{B}$. Between these two values of $H$ there are values of $B$ for which the short plate solution of equation (4) gives a higher upper bound than the long plate solution in equation (3). In these cases, the long plate solution, giving the minimum upper 

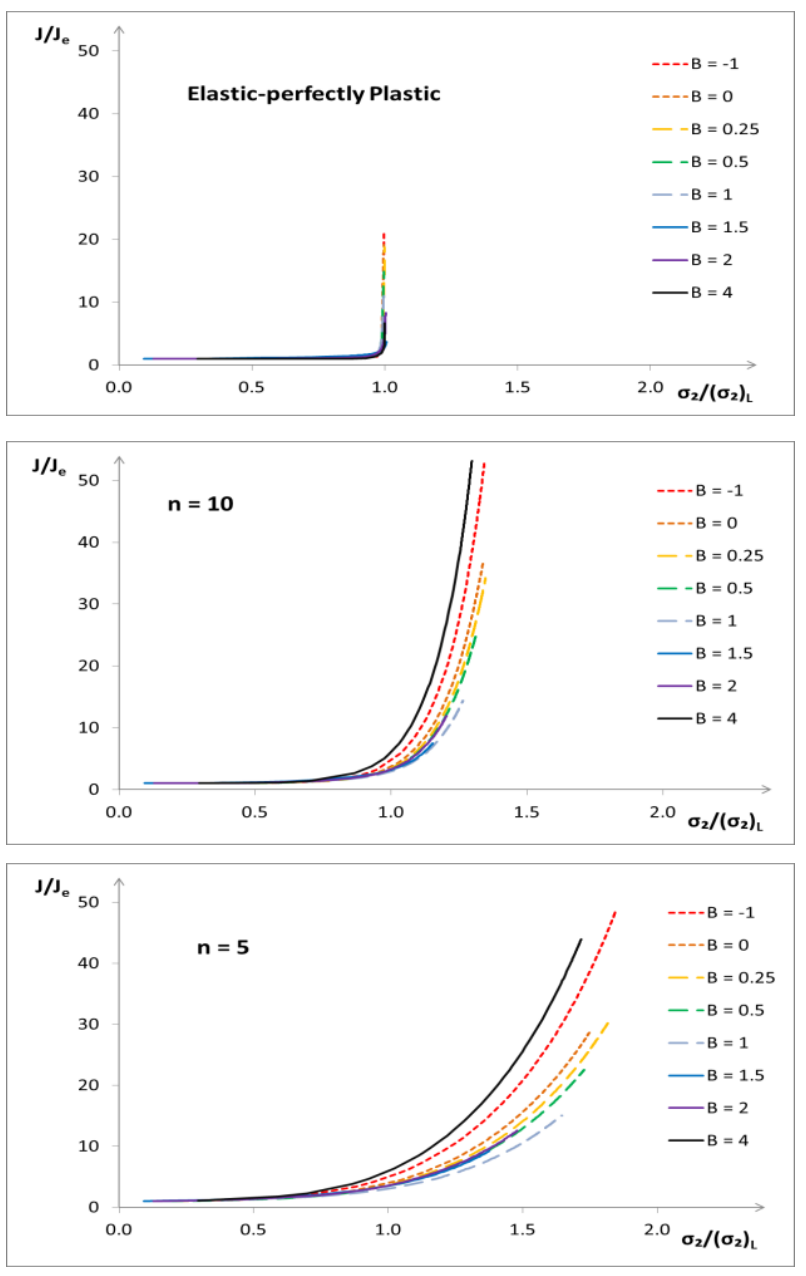

Figure 4: Normalised $\mathrm{J}$ integral for varying $\mathrm{n}, \mathrm{a} / \mathrm{W}=\mathbf{0 . 6}$

bound, will be the limit load solution. More details of this are given in [6].

\section{J SOLUTIONS FOR NON-LINEAR MATERIALS}

Using the same centre cracked plate model as has been used for an elastic-perfectly plastic material, the normalised J (energy release rate) FE output has been plotted here for materials following a Ramberg-Osgood power law relationship, equation (5), with work hardening exponents $\mathrm{n}=5$ and $\mathrm{n}=10$.

$$
\frac{\varepsilon}{\varepsilon_{0}}=\frac{\sigma}{\sigma_{\mathrm{y}}}+\alpha\left(\frac{\sigma}{\sigma_{\mathrm{y}}}\right)^{\mathrm{n}}
$$

Fixing the yield offset, $\alpha \sigma_{y} / E$, at 0.002 , i.e. a proof strain of $0.2 \%$, equation (5) can be written as

$$
\varepsilon=\frac{\sigma}{E}+0.002\left(\frac{\sigma}{\sigma_{\mathrm{y}}}\right)^{\mathrm{n}}
$$

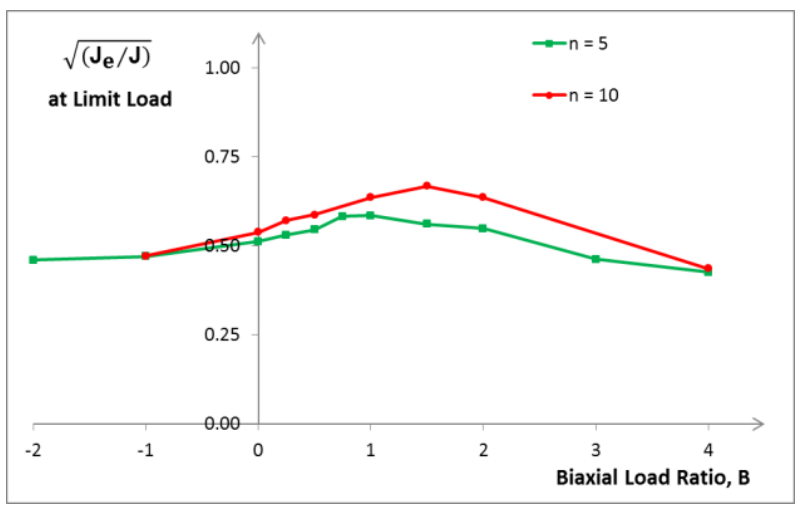

Figure 5: Effect of biaxial ratio on $\sqrt{\left(\mathrm{J}_{\mathrm{e}} / \mathrm{J}\right)}$, for power-law hardening materials, $\mathrm{a} / \mathrm{W}=\mathbf{0 . 6}$

The values of $\mathbf{J}$ calculated for this model during loading have been normalised by the elastic value of $\mathbf{J}$ for the same applied loading and plotted against the applied load normalised by the finite element limit load (Figure 4) for a centre cracked plate with crack width $\mathrm{a} / \mathrm{W}=0.6$.

For the power-law hardening materials, it can be seen that the near-elimination of biaxial effects after normalisation that is observed for an elastic-perfectly plastic material does not occur and that the influence of biaxiality seems to increase with decreasing $\mathrm{n}$. The extent of the influence is shown in Figure 5 where the variable $\sqrt{\left(\mathrm{J}_{\mathrm{e}} / \mathrm{J}\right)}$, which is essentially the ordinate of the failure assessment diagram (FAD) termed Option 3 in R6 [1], is plotted at the limit load ratio $\left(\sigma_{2}\right)_{\mathrm{L}} / \sigma_{\mathrm{y}}=1$. For $\mathrm{n}=10$, for values of biaxial load ratio $\mathrm{B}$ between $\mathrm{B}=0$ (uniaxial loading) and $\mathrm{B}=3$, the value of $\sqrt{\left(\mathrm{J}_{\mathrm{e}} / \mathrm{J}\right)}$ is greater than that of the uniaxial loading $(\mathrm{B}=0)$ making the uniaxial FAD conservative when these levels of biaxial loading are applied. Outside these values, where B $<0$ (compressive loading) and $\mathrm{B}>3$ (high biaxial tensile force), $\sqrt{\left(\mathrm{J}_{\mathrm{e}} / \mathrm{J}\right)}$ is less than that for uniaxial loading at the same normalised load level.

\section{SINGLE AND DOUBLE EDGE CRACKED PLATE LIMIT LOAD ESTIMATES}

Limit load solutions for double and single edge cracked plates have been estimated here by using the uniaxial limit load solutions in R6 [1] and applying the von Mises biaxial stress field method that was used to obtain lower bound limit load solutions for the centre cracked plates.

The R6 plane strain Mises solutions for normalised limit loads for double edge cracked and single edge cracked plates under uniaxial loading are of the form of equation (7).

$$
\mathrm{n}_{\mathrm{L}}=\frac{\left(\sigma_{2}\right)_{\mathrm{L}}}{\sigma_{\mathrm{y}}}=\gamma \mathrm{f}(\beta)
$$



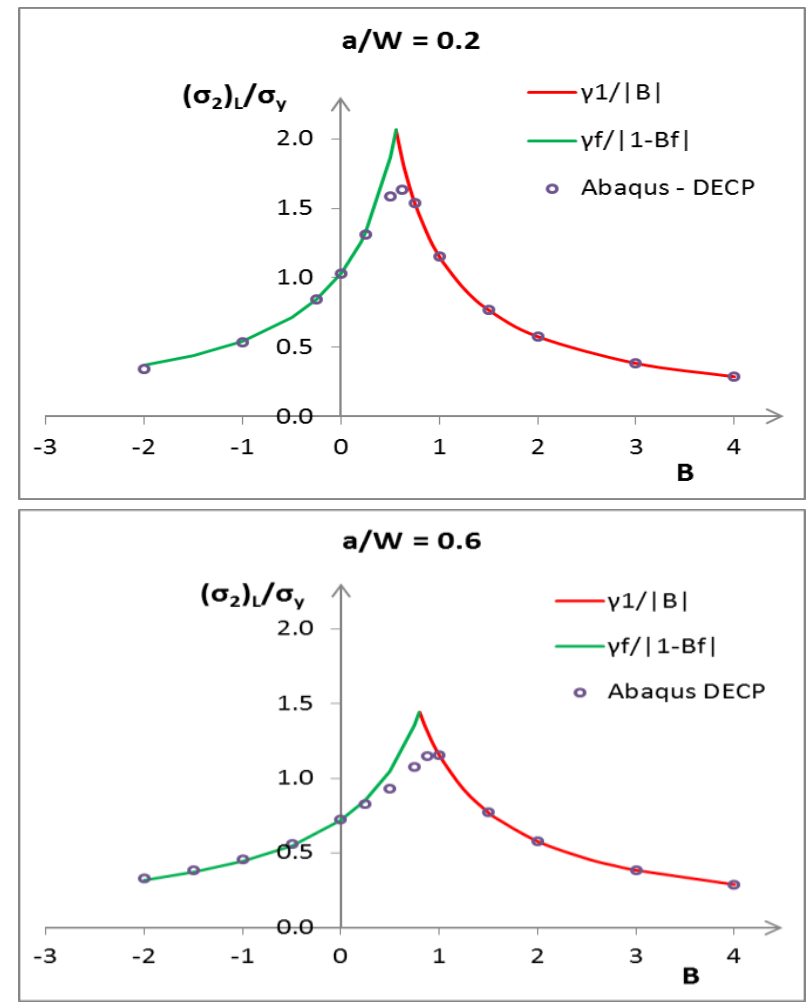

Figure 6: Limit load solutions for double edge cracked plates

where $\gamma=2 / \sqrt{3}, \beta=\mathrm{a} / \mathrm{W}$ and $\mathrm{f}(\beta)$ is a function of $\beta$ which represents the limit load solutions, also given by Miller [7].

The solutions found for this study from this approach are of the form of equation (8).

$$
\left(\sigma_{2}\right)_{\mathrm{L}}^{\mathrm{lb}}=\frac{2 \sigma_{\mathrm{y}}}{\sqrt{3}} \operatorname{Min}\left[\frac{1}{|\mathrm{~B}|}, \frac{\mathrm{f}(\beta)}{|1-\operatorname{Bf}(\beta)|}\right]
$$

\section{DOUBLE EDGE CRACKED PLATES}

The limit load solution for a double edge cracked plate in R6 is reproduced here in equation (9).

$\mathrm{n}_{\mathrm{L}}=\frac{\left(\sigma_{2}\right)_{L}}{\sigma_{y}}= \begin{cases}\gamma(1-\beta)\left[1+\ln \left(\frac{2-\beta}{2(1-\beta)}\right)\right] & \text { for } 0 \leq \beta \leq 0.884 \\ 2.57 \gamma(1-\beta) & \text { for } 0.884<\beta<1\end{cases}$

i.e. for $0 \leq \mathrm{a} / \mathrm{W} \leq 0.884$,

$$
f(\beta)=\gamma(1-\beta)\left[1+\ln \left(\frac{2-\beta}{2(1-\beta)}\right)\right]
$$

Thus an approximate lower bound solution for a double edge cracked plate with tensile stress $\sigma_{2}$ applied normal to the crack and a biaxial stress $\mathrm{B}_{2}$ (tensile or compressive) applied parallel to the crack is found by applying the formula in equation (8) to equation (10), leading to equation (11) for the range of a/W considered.

$\left(\sigma_{2}\right)_{\mathrm{L}}^{\mathrm{lb}}=\frac{2 \sigma_{\mathrm{y}}}{\sqrt{3}} \operatorname{Min}\left[\frac{1}{|\mathrm{~B}|}, \frac{(1-\beta)\left[1+\ln \left(\frac{2-\beta}{2(1-\beta)}\right)\right]}{\left(1-\mathrm{B}(1-\beta)\left[1+\ln \left(\frac{2-\beta}{2(1-\beta)}\right)\right]\right)}\right]$

Finite element analyses were carried out using the same basic quarter model used for the centre cracked plate but changing the boundary conditions and location of the symmetry plane to model a double edge cracked plate.

The maximum load values in the FE analyses are plotted together with values of $\sigma_{2}$ in equation (11) against biaxial ratio $\mathrm{B}$ for crack sizes $\mathrm{a} / \mathrm{W}=0.2$ and $\mathrm{a} / \mathrm{W}=0.6$ (Figure 6). There is good agreement for both crack sizes between the limit loads estimated using equation (11) and the FE output, particularly for values of $\mathrm{B} \leq 0.25$ and $\mathrm{B} \geq 1$.

\section{SINGLE EDGE CRACKED PLATES}

The limit load solution for a single edge cracked plate in R6 is reproduced here in equation (12).

$\mathrm{n}_{\mathrm{L}}=\frac{\left(\sigma_{2}\right)_{\mathrm{L}}}{\sigma_{\mathrm{y}}}=$

$\begin{cases}\gamma\left[1-\beta-1.232 \beta^{2}+\beta^{3}\right] & \text { for } 0 \leq \beta \leq 0.545 \\ 1.702 \gamma\left[\sqrt{\left[(0.794-(1-\beta))^{2}+0.5876(1-\beta)^{2}\right]}-(0.794-(1-\beta))\right] & \text { for } 0.545<\beta<1\end{cases}$

Combining equation (8) with equation (12) for $\mathrm{a} / \mathrm{W}=0.2<0.545$ leads to

$\left(\sigma_{2}\right)_{\mathrm{L}}^{\mathrm{lb}}=\frac{2 \sigma_{\mathrm{y}}}{\sqrt{3}} \operatorname{Min}\left[\frac{1}{|\mathrm{~B}|}, \frac{\left(1-\beta-1.232 \beta^{2}+\beta^{3}\right)}{\left|1-\mathrm{B}\left(1-\beta-1.232 \beta^{2}+\beta^{3}\right)\right|}\right]$

Combining equation $\mathrm{a} / \mathrm{W}=0.6>0.545$ leads to
(8) with equation (12) for 

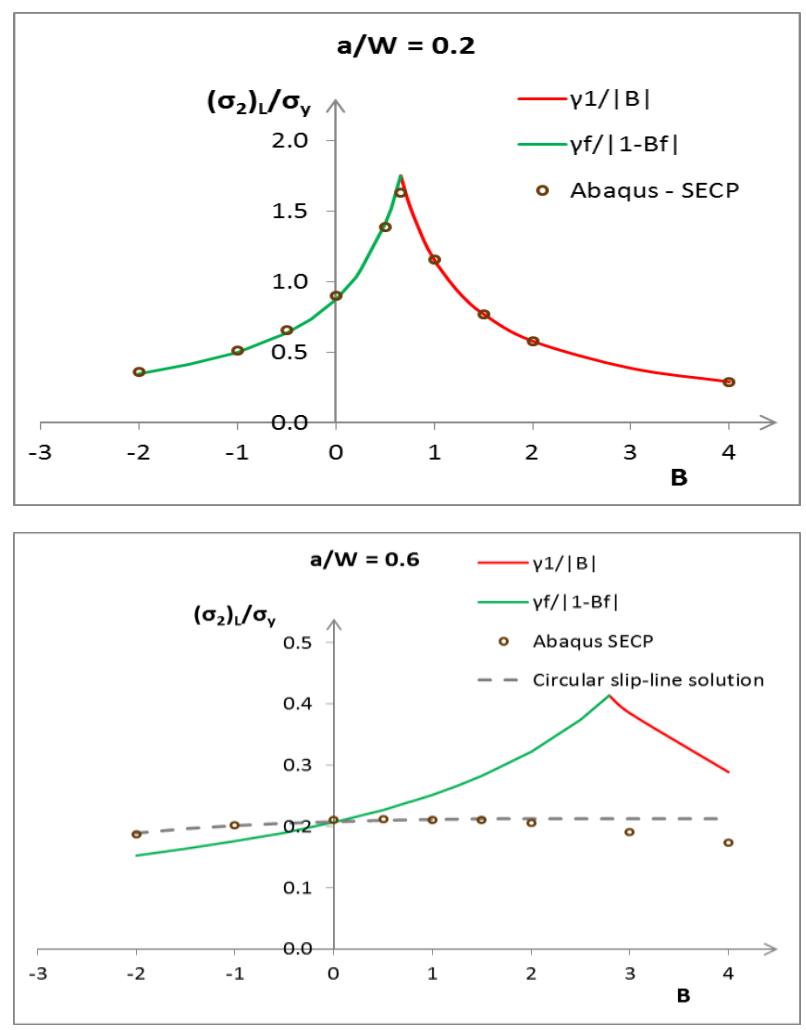

Figure 7: Limit load solutions for single edge cracked plates

$=\frac{2 \sigma_{\mathrm{y}}}{\sqrt{3}} \operatorname{Min}\left[\frac{1}{|\mathrm{~B}|}, \frac{1.702 \sqrt{\left[(0.794-\mathrm{z})^{2}+0.5876 \mathrm{z}^{2}\right]}-(0.794-\mathrm{z})}{\mid\left(1-\mathrm{B}\left[1.702 \sqrt{\left[(0.794-\mathrm{z})^{2}+0.5876 \mathrm{z}^{2}\right]}-(0.794-\mathrm{z})\right]\right.}\right) \mid$

where $\mathrm{z}=(1-\beta)$

Figure 7 shows that for $\mathrm{a} / \mathrm{W}=0.2$ there is excellent agreement between the limit load values estimated using equation (13) and the FE output. However for a/ $\mathrm{W}=0.6$ there is reasonable agreement when $\mathrm{B}<1$ but none at all above this value. There will be a maximum value of $\mathrm{a} / \mathrm{W}$, therefore, for which the solution is valid. Further work is ongoing to assess this value together with a more accurate method of determining the limit loads for single edge cracked plates with crack widths above this maximum value.

\section{DISCUSSION}

Short plate upper bound limit load solutions for a centre cracked plate found using slip-line analysis show excellent agreement with the FE limit loads, which validates their use for limit loads biaxial loading. Approximate lower bound limit load solutions for double and single edge cracked plates have been shown to be in excellent agreement with finite element solutions for many values of $\mathrm{a} / \mathrm{W}$ and $\mathrm{B}$, but further work is needed to provide solutions for values of $\mathrm{B}$ close to $\mathrm{B}=1$, equibiaxial loading, and for single edge cracked plates for crack widths above $\mathrm{a} / \mathrm{W}=0.2$.

Slip-line analyses, using straight and circular slip-lines have been carried out for single and double edge cracked plates to provide upper bounds for the limit loads. The approach is similar to that performed for the centre cracked plates in [3] and details are omitted here for brevity. The results for the circular slip-line upper bound solution for a single edge cracked plate with $\mathrm{a} / \mathrm{W}=0.6$ are included in Figure 7 and these are in very good agreement with FE results for a wide range of $\mathrm{B}$.

Some $\mathbf{J}$ solutions for power-law hardening materials for centre cracked plates show that, in contrast to elastic-perfectly plastic material, where the influence of biaxial loading is mostly eliminated once normalisation by the limit load is used, [3], the level of the biaxial loading can lead to an increase or decrease in the normalised crack driving force depending on the biaxiality, B.

Ongoing work will involve the analysis of biaxial fracture experiments to assess the extent to which the limit loads can be used for fracture analysis as well as limit analysis.

\section{ACKNOWLEDGMENTS}

The authors gratefully acknowledge the support of EPSRC, EDF Energy and AMEC Foster Wheeler.

\section{REFERENCES}

[1] EDF Energy Nuclear Generation Ltd, 2015, "R6: Assessment of the Integrity of Structures Containing Defects," Revision 4, EDF Energy Nuclear Generation Ltd, Gloucester.

[2] British Standards Institution, 2013, “BS 7910:2013 Guide to methods for assessing the acceptability of flaws in metallic structures" BSI, London.

[3] Meek C., and Ainsworth R. A., 2014, "PVP201428317 Ductile fracture assessment of plates under biaxial boading," Proceedings of the ASME 2014 Pressure Vessels \& Piping Division Conference, Anaheim, California, USA, July 20-24, 2014.

[4] Østby E., and Hellesvik A. O., 2008, "Large-scale experimental investigation of the effect of biaxial loading on the deformation capacity of pipes with defects," International Journal of Pressure Vessels and Piping, 85(11), pp. 814-824. 
[5] O'Dowd N. P., Kolednik O., and Naumenko V., 1999, "Elastic-plastic analysis of biaxially loaded centercracked plates," International Journal of Solids, 36, pp. 5639-5661.

[6] Meek C., and Ainsworth R. A., 2014, "Fracture assessment of centre-cracked plates under biaxial loading," Procedia Materials Science, 3, pp. 16121617.

[7] Miller A. G., 1988, "Review of limit loads of structures containing defects," International Journal of Pressure Vessels and Piping, 32, pp. 197-327. 